\title{
Designing an Adaptive Learning Environment to Improve Writing Skills and Usability for EFL Students at the Faculty of Education
}

\author{
Prepared by
}

\author{
Rehab Hamadtoh Abu Al-Ghait Gohar \\ Lecturer of Curriculum \& Instruction: TEFL \\ Faculty of Education -Mansoura University \\ gohar_rehab@yahoo.com
}

\author{
Dr. Reham Mohamed Ahmed El-Ghool \\ Lecturer of Instructional Technology \\ Faculty of Education- Mansoura University \\ drreham80@gmail.com
}

\section{Abstract:}

Learning characteristics vary for each individual learner. Research suggests that knowledge is processed and represented in different ways and that students prefer to use different types of resources in distinct ways. Adapting learning to meet the various individual differences of the students is a real challenge. Thus, the present study aimed at investigating the effect of designing an adaptive learning environment on developing EFL undergraduate students' writing skills and usability. A design standards checklist was prepared for guiding the process of designing the proposed online adaptive environment. The multiple intelligences (MI) theory was used as a basis for conducting the adaptation process since the students were divided according to their strong intelligences into three groups (analytic, introspective and interactive groups). Different types of multiple intelligences-based activities were presented to each group. Those activities were also adapted according to the writing level of the students (beginning, intermediate and advanced). Consequently, each student proceeded in the adaptive environment in an individualized learning path which was pre-determined through the student MI profile (including a student's personal data, EFL writing level and multiple intelligences).Various online tools (hangouts, Google drive, Facebook and WhatsApp) were employed in the adaptive environment. The experimental design was adopted using 60 students of the $2^{\text {nd }}$ year English major at Mansoura Faculty of Education. Those participants were divided into two groups: one experimental and one control. Instruments used in the present study were: 1) an EFL writing skills test, 2) an analytic rubric for scoring the writing skills, and 3) a usability scale to evaluate the easiness of students' learning through the adaptive environment. The 
results indicated that the adaptive online learning environment led to developing EFL students' writing skills and that the students found the environment usable for learning and interacting with fellows and instructor.

\section{Key words:}

Adaptive learning environment, multiple intelligences, EFL writing skills, usability.

\section{Introduction:}

Traditional educational systems tend to adopt a 'one size fits all approach' and deal with all students in the same manner. However, this raises many problems since they are students with different levels of knowledge, goals and preferences, characteristics, learning styles and multiple intelligences. Adaptive and online educational systems overcome this problem by using a flexible generated model to dynamically adapt the learning environment for each student in a manner that best supports his/her needs; thus, students' individual differences can be met easily through the numerous variations that can be offered online or electronically.

The rapid development of information and communication technologies (ICT), internet technologies and web-based applications have initiated a rapid transformation in universities all over the world. Online learning is changing the way teaching and learning is taking place on university campuses especially in the areas of content delivery, assessment and communication. In all levels, starting from kindergarten till after university level, learners can use the various interactive e-learning tools to develop their skills, knowledge and perception of the world. It is time for traditional education to be replaced with up-to-date personalized online learning systems that can be tailored in response to students' individual differences.

Sonwalkar (2005) illustrated that it is essential for higher education programs to support the integration of online learning and adaptive learning systems since such systems offer multiple pedagogical choices and instructional support for faculty and a rich educational experience for students. It was added also that while course management systems continue to provide access and convenience of sharing data, adaptive learning systems that provide learning experiences tailored to students' preferences, real-time continuous feedback, enhanced assessment tools, and rich interactive opportunities are evolving as the next generation of educational technology. 
In the field of teaching and learning English, it was indicated that online learning can enhance students' achievement in EFL reading, writing, grammar, vocabulary and critical thinking (Zang, et al., $2007 \&$ Isa, 2012). The current study tried to make use of the various opportunities offered through adaptive online learning to develop writing skills for the EFL undergraduate students at Mansoura Faculty of Education.

\section{Review of related literature:}

Writing well is not just an option for young people - it is a necessity. Along with reading comprehension, writing skill is a predictor of academic success and a basic requirement for participation in civic life and in the global community. Adult learners of English have many reasons for mastering writing skills. They may need to write to carry out functional tasks such as filling out forms, taking a message, or writing email messages. Others may need writing skills to succeed in academic studies or to advance in a job. For many learners, writing is important for putting their thoughts on paper and sharing them with others.

Writing is considered a complex process that involves constructing meaningful and grammatically correct sentences. Nunan (2003) explained that writing is the process of thinking to invent ideas and arrange them into statements and paragraphs so as to produce good writing. Besides, Isleem (2012) indicated that writing is important in helping students to express their thoughts and feelings. It is also essential for developing students' linguistics, concepts, idioms and grammar.

Writing is a major skill that includes various sub-skills. Gabrielatos (2002) stated that writing skills include: correct spelling, correct use of grammar and appropriate word choice; good layout and organization; cohesion, coherence and unity. For teaching writing, there are two approaches: product writing and process writing. According to the product approach, the focus is on producing a text (the product). This approach neglects outlining the text, planning and collecting ideas. On the contrary, the process approach argues that writers do not start with a clear idea of the finished product. Rather, the text emerges out of a creative process. This process includes: planning (generating ideas, goal setting and organizing), drafting and re- drafting, reviewing including editing and proofreading, and, finally, publishing (Franco, 2008). Consistently, Hartly (2008) indicated that writing typically consists of 4 main stages: planning, writing, editing and reviewing. As writing is an iterative process, these activities do not occur in a fixed order; rather, writers move among these activities although typically, 
more time is spent on planning or thinking at the start and on editing and reviewing at the end.

Despite the importance of writing skills, many researchers indicated that it is the most difficult task. For example, Johnstone (2002) emphasized that writing is the most difficult language activity due to the cognitive processes of generating ideas and translating them into sentences. Furthermore, Wang (2005) illustrated that writing is a problem for many teachers. They spend a lot of time correcting students' writing; but still students' writing remain poor, grammatically incorrect and deprived of sentence structure variety. In addition, Kellogg \& Raulerson (2010) indicated that the 2002 National Assessment of Educational Progress assessed the writing preparedness of American students. It was revealed that a high percentage of the students did not practice writing at a satisfactory level. This is the case of native English students, what about EFL students' writing in Egypt or in the Arab World?

AbuArmana (2011) indicated that students at UNRWA schools in Rafah had weaknesses in their EFL writing skills, and thus, a remedial program was conducted to improve those skills. The program proved its effectiveness in developing EFL students' writing skills. In addition, Nazim (2012) emphasized that EFL students had a lot of writing problems and that they considered writing as the most difficult language task. Examples to EFL students' writing problems included: punctuation, spelling, language use and grammar. Consistently, Salem (2013) stated that EFL undergraduate students at Hurghada Faculty of Education had many writing difficulties. A writing workshop approach program was designed and used as a remedy to those students. Results indicated that the program affected EFL undergraduate students positively.

Moreover, Hassan (2016) investigated the impact of grammatical errors on EFL learners' writing. The areas which the study investigated were subject verb agreement, the prepositions and past simple versus present perfect. The study population was composed of $4^{\text {th }}$ year students studying English language at the college of languages, Sudan University of science and Technology. The data collection tool was a test given to the students to write a composition. Findings concluded that most of the students are unable to understand and deal with the prepositions in writing, most students failed to use subject verb agreement which is a big problem that hinder students' self-expression.

In order to address EFL students' writing difficulties and adhering to the principle that "one size does not fit all", an adaptive system would provide an advanced form of learning environment that attempts 
to meet the different needs of different students. Khamis (2015) summarized that adaptive learning can be based on many different ability and aptitude variables such as intellectual style, cognitive styles, learning styles, prior knowledge, self-efficacy, multiple intelligences, anxiety, motivation and locus of control. According to the present study, multiple intelligences theory was used as a basis for designing dynamic adaptation of the learning environment for each student in a personalized manner that best supports learning.

According to Gardner's theory of Multiple Intelligences, students possess different kinds of intelligence and therefore learn, remember, perform, and understand in different ways. Kelly (2008) mentioned that intelligence is the bio-psychological potential to process information that can be activated in a cultural setting to learn and solve problems. The Multiple Intelligence theory states that there are nine different ways to demonstrate this intelligence with each having its own unique characteristics, tools, and processes that represent a different way of thinking, solving problems, and learning. The nine intelligences include the logical/mathematical, linguistic/verbal, visual/spatial, bodily/kinesthetic, musical/rhythmic, interpersonal, intrapersonal, naturalist and existential intelligence. Gardner (1983) suggested that everybody has different intelligences to different degrees and that they operate together in harmony. The theory suggests that even though different intelligences tend to be stronger in some people, everybody has the capacity to activate all the intelligences, and in different situations distinct intelligences or a combination of intelligences may be used.

Many researchers indicated that designing multiple intelligencesbased activities improves EFL students' writing skills. For example, El-Masrafy (2003) assessed the use of a program based on multiple intelligences on enhancing EFL students' composition writing skills. Examples to the activities used in the study included journal writing and analyzing a video show. Findings supported the value of using multiple intelligences-based activities to improve EFL writing skills. These findings were supported by El-Embaby (2008) and Ahmadian \& Hosseini (2012) in their studies about using multiple intelligences theory to develop EFL students' writing performance. Consequently, the multiple intelligences theory was considered as a good option for improving writing skills and designing the proposed adaptive online learning environment which is the core of the present study.

Imagine an adaptive learning environment where students actively engage in rich and diverse experiences that motivate and inspire them. Picture them living real world challenges, resolving complex 
problems, and participating in authentic learning situations. Envision these students using problem-solving, critical thinking, and learning skills in practical and innovative ways. The different tasks that students accomplish in a rich online environment enable them to produce good writing, projects, experiments, presentations, portfolios, and other innovative products of their learning. Adaptive online learning is supposed to do all the above through enriching students' learning with more multiple tasks in an attractive, interactive, collaborative and upto-date instructional style while using their needs, characteristics, language levels, and multiple intelligences as a basis for such an individualized learning.

$\mathrm{Li}$, et al. (2010) stated that adaptive learning is mainly based on the constructivist theory and the theory of cognitive flexibility. Adaptive learning is a way of learning in which learners acquire knowledge and skills through positive thinking and operation. It is an active learning approach since learners can monitor their own learning, and choose the most suitable learning content and strategies according to their actual needs. Similarly, Francois (2011) regarded adaptive learning as a usage of technology to help the students in individualizing their learning process.

Oxman \& Wong (2014) also described adaptive learning as a learning process where the content taught or the way such content is presented differs, or "adapts," based on the responses of the individual student. The goal of an adaptive learning system is to personalize instruction in order to improve or accelerate a student's performance gain. At their core, such systems are intended to identify what a student does and does not understand, identify and provide content that will help the student learn it, assess again, help again, etc., on a continuous basis until a target learning goal is achieved.

Khamis (2015) stated that the term adaptive e-learning refers to the ability of a system of e-learning to provide courses and learning objects tailored to the instructional needs of the learner. The main goals of adaptive systems include:

1. Delivering the right content, to the right person, at the proper time.

2. Presenting flexible instructional variations.

3. Providing instructional pathways that can accommodate learning styles and learning strategies.

4. Monitoring educational processes, generating reports and providing guidance more effectively.

5. Providing formative intelligent feedback. 
Li, et al. (2010) also explained that the main features of adaptive online learning include:

\section{-A personalized learning system with the learner as the main}

body: according to the learner's learning needs, learning ability and learning style, the system actively adjusts the learning content, learning style, learning strategy, learning paths and learning support, making the difficulty of learning materials suited to the learner's level, the presented learning content suited to the learner needs, and the provided guidance suited to the learner's learning strategies.

-The self-construction of knowledge: learners actively interact with adaptive learning system, constantly obtain and analyze feedback information, so as to construct their knowledge. Through adaptive learning, learners can timely control and adjust their own learning process to achieve their target learning goals.

-The adaptive learning system is intelligent: intelligence is the basic guarantee for the system to realize self-adaptation. It enables the system to make comprehensive diagnose of the learner's actual level and preferences, and present appropriate learning content and support according to the pre-testing and learning process tracking.

Both Khamis (2015) and Murray \& Perez (2015) agreed that there are three levels or approaches to adaptive learning. At the macro-level, instruction is adapted by altering instructional goals, delivery systems, or curriculum, enabling adaptation at many dimensions including navigation, assessment, and presentation. Mid-level systems facilitate the adaptation of instructional strategies. A simple example of these systems is one that modifies content presentation by medium (audio, visual, video) based on learning preferences indicated by students. At the micro-level, instruction is adapted in real-time as student learning needs are diagnosed and instructional treatments prescribed.

Mödritscher (2007) emphasized the importance of a fourth approach which is the constructivist-collaborative approach. This is a result of the merits of effective collaborative learning which are: (1) participation, (2) social behavior, (3) performance analysis, (4) group processing and conversation skills and (5) primitive interaction. Employing such features, adaptive online courses could be extended from instructional design for individual learners to collaborative activities for groups of learners.

Surjono (2014) listed the basic components of an adaptive learning environment: the domain model, the student model and the adaptation model. The domain model is the area or topic for which adaptive learning is intended as a resource. The student model is a collection of characteristics for which specific values are recorded for each user. 
The adaptation model refers to what parts of the e-learning can be adapted and under what circumstances this adaptation is to occur.

Similarily, Klašnja-Milićević\& et al. (2017) illustrated that three essential types of adaptation have been proposed in literature:

1. Interface-based (also known as adaptive navigation): it relates to elements and options of the interface like usability and adaptability: where particular elements are employed on the screens (e.g. size, color, etc.).

2. Learning flow-based: the learning process is dynamically adapted in appropriate (different) ways through which the content is delivered.

3. Content-based: the resources and activities dynamically change their actual content (for example systems based on adaptive presentation).

Adaptive learning is a recent area of research and investigation especially in the field of teaching and learning English. Khodabakhshzadeh \& Kondori (2016) investigated the use of adaptive reading story to develop reading comprehension ability outside the classroom. Participants of the study included 50 male intermediate EFL learners, divided into two control and experimental groups after passing the homogenizing test. The control group received a regular reading class while the experimental group received an adaptive reading story out of the class. The findings showed that adaptive reading story in the experimental group had much more significant effects on improving learners' reading comprehension ability. This provided pedagogical implications for adaptive reading story as an effective learning tool for EFL students that can be utilized by teachers at different levels of language education in order to maximize the effectiveness of students' learning.

Furthermore, Hussani, Nahvi \& Ahmadi (2013) examined the impact of an adaptive virtual environment for language learning to improve listening and speaking skills of non-native English language learners. The proposed environment supports visual, auditory, and haptic channels of interaction. The researchers designed a computational model to evaluate learner's proficiency level, and an automatic adaptation mechanism which adjusts to the learner's learning curve. Throughout interactions, agents discover the proficiency level of the learner and customize the level of communication complexity accordingly. Experimental results revealed $14 \%$ increase in the number of proper replies, $3 \%$ decrease in grammatical errors, $16 \%$ decrease in pronunciation duration, and $11 \%$ increase in learners' proficiency level. 
Besides, Asl, Ghassemi \& Madadi (2014) examined if peercooperative reading e-materials adaptation has any effect on learners' participation in online reading classes. Participants included 90 Iranian students who were studying at Noor Language Center which offers online courses as well as the chalk-and board ones. The selection was on the basis their scores obtained in TOEFL (a language proficiency test). The findings showed that involving the students in the adaption process of reading e-materials improved their reading comprehension performance.

Alshammari, et al. (2016) examined designing effective adaptive elearning systems, from a usability perspective since this represents a challenge because of the complexity of adaptivity in order to meet the diverse requirements of learners. Results indicated that an adaptive elearning system based on learner knowledge and learning style has a higher level of perceived usability than a non-adaptive e-learning system. This may also increase the level of satisfaction, engagement and motivation of learners and therefore enhance their learning.

Moreover, Kelly (2005) used Gardner's theory of Multiple Intelligences (MI) as the basis for modeling learning characteristics and for developing different Multiple Intelligence informed versions of the same instructional material. The study explored: 1) the impact of using different adaptive presentation strategies in contrast to giving the learner complete control over the learning environment and 2) the effect on learning performance when material is matched and mismatched with learning preferences. Results suggested that teaching strategies can improve learning performance by promoting a broader range of thinking and encouraging students to transcend habitual preferences. In particular, they suggest that students with low levels of learning activity have most to benefit from adaptive presentation strategies and that surprisingly learning gain increases when they are provided with resources not normally preferred. These results were supported by Kelly (2008) when the same study was re-administered.

Despite the various advantages of adaptive learning; still, it has some concerns and challenges. Kara \& Sevin (2013) clarified that although the merits of adaptive learning are dreams of all educators, the implementation of such adaptive systems is a real challenge. Adaptation depends mainly on determining individual differences; then, it may cause problems if these differences and appropriate methods/materials to address them are not identified correctly. It is very important to get information to form a learner model. However, which information should be obtained to create a successful user model and how should it be obtained? Should the system trust the 
learner to decide the appropriate method for their learning? Moreover, it is important to identify what to adapt. The system has to identify some differences such as background, prior knowledge about the content, learning style and offers a learning environment to suit these differences. If the systems are not carefully designed, it will not bring advantages, only cause problems. The maintenance of adaptive systems is an additional weakness which can hinder the effectiveness of adaptive learning systems. Since technological knowledge of the teachers may not be adequate to maintain such kind of systems, or students may lack the technological knowledge to overcome the problem when they face one. Murray \& Perez (2015) compared an adaptive learning system with a traditional objective assessment approach to instructional content delivery and assessment in a digital literacy course. Findings indicated that student learning did not vary significantly across the informing and performing 124 courses based upon instructional delivery approach.

From what has been mentioned above, it is obvious that many studies recommended e-learning over traditional learning especially in higher education. Time constraint on today's students coupled with the need for education to keep up with students' needs and individual differences as well as the advances in technology has forced educators to facilitate adaptive teaching/learning avenues other than traditional methods. Studies emphasized the effectiveness and significance of using adaptive learning to support students' in different areas of study. However, Kara \& Sevin (2013) and Murray \& Perez (2015) had some concerns about the difficulties and challenges of applying adaptive elearning systems. Yet, the current study attempted to reach a reality concerning the effectiveness of using adaptive learning to improve EFL undergraduate students' writing skills.

\section{Statement of the problem:}

Based on the previous background, the researcher's observation and direct contact with the students in the TEFL skills lab or in the microteaching session, it was noticed that $2^{\text {nd }}$ year English major students at the Faculty of Education need to improve their EFL writing skills. Thus, the current study aimed at investigating the effectiveness of a proposed adaptive learning environment in improving $2^{\text {nd }}$ year English major students' EFL writing skills, in addition to assessing the usability of the adaptive environment for the target participants.

\section{Questions of the Study:}

The present study answered the following questions: 
1. What are the EFL writing skills necessary for $2^{\text {nd }}$ year English major students at the Faculty of Education?

2. What are the instructional design standards required for designing the adaptive learning environment?

3. What is the instructional design of the adaptive learning environment proposed for improving $2^{\text {nd }}$ year English major students' EFL writing skills?

4. What is the effectiveness of the adaptive online learning environment in improving $2^{\text {nd }}$ year English major student teachers' EFL writing skills?

5. To what extent is the adaptive online learning environment usable for the students?

\section{Purpose of the Study:}

The current study aimed at investigating the effect of the proposed adaptive online learning environment on developing EFL undergraduate students' writing skills; besides, the usability of the proposed adaptive environment was also investigated.

\section{Delimitations:}

The study was delimited to the following:

1. Some EFL writing skills necessary for $2^{\text {nd }}$ year English major students at the Faculty of Education (content-related skills, stylerelated skills, writing mechanics and grammar).

2. A sample of $2^{\text {nd }}$ year English major undergraduate students at Mansoura Faculty of Education.

3. An adaptive learning environment employing some online tools (Google Drive, Facebook, Hangouts and WhatsApp) in the adaptation process.

4. Using multiple intelligences theory as the basis for conducting the online adaptation. An adapted version of MIDAS (multiple intelligences development assessment scale) MI Inventory was used to determine students' preferred multiple intelligences. The MIDAS was used for two major characteristics: 1) results are easily understood because the items possess an everyday common-sense meaning, and 2) results may be easily translated in terms of predicting potential success in various activities (Al-Onizat, 2014).

\section{Operational definition of terms:}


Writing skills: refer to the ability to express one's thoughts and feelings through writing in an organized and intelligible way producing relevant and adequate content, proper spelling and punctuation, correct grammar, varied sentence structures, proper vocabulary, good coherence and appropriate use of cohesive devices.

Adaptive learning environment: is an interactive learning system where the content or the way of its presentation is tailored or adapted according to students' multiple intelligences and EFL writing level. The major goal of the adaptive environment is to direct students to personalized learning pathways that best suit their needs. This online environment allows for monitoring students' learning progress and providing continuous support and feedback till reaching the target skills.

Usability: refers to the ability of the $2^{\text {nd }}$ year EFL students at the Faculty of Education to interact with the adaptive learning environment in a positive way to fulfill the required learning activities in their personalized learning paths. Standard usability principles of the adaptive environment include consistency, privacy and learner controllability.

\section{Instruments:}

For the purpose of the study, the following instruments were designed and implemented by the researchers:

1. A checklist for identifying the EFL writing skills required for the target participants.

2. A standards checklist for designing the proposed adaptive online learning environment.

3. A test for assessing students' EFL writing skills.

4. An analytic rubric for assessing and scoring students' EFL writing skills.

5. A usability scale for assessing the usability of the proposed adaptive learning environment.

\section{Hypotheses:}

The present study tested the following hypotheses:

1. There is a statistically significant difference at 0.05 level between the mean scores of the control group and the experimental group on the post application of the EFL Writing test in favor of the experimental group. 
2. There is a statistically significant difference at 0.05 level between the mean scores of the experimental group pre-post application of the EFL writing test in favor of the post application.

3. The effectiveness of the adaptive learning environment in developing students' EFL writing skills is more than (1.2) when measured by Black's modified gain percentage and more than (0.6) when measured by Mac Gogian's effectiveness percentage.

4. There is a statistical significant difference at 0.05 level between the mean scores of the experimental group when applying the usability scale and the hypothetical mastery level (90\%) in favor of the usability scale.

\section{Participants:}

The experiment involved the participation of 60 undergraduate students in the $2^{\text {nd }}$ year, English major, at Mansoura Faculty of Education. They were divided into two groups: one control and one experimental; and each group consisted of 30 students.

\section{Design:}

The study adopted the experimental design using two groups. The experimental group received the proposed multiple intelligences-based adaptive online learning environment, while the control group received the regular writing course through Moodle (since Mansoura University made Moodle use available for free). Both groups received the preand post-application of the EFL writing test. The usability scale was applied only to the experimental group only.

\section{Procedures:}

\section{First, designing the instruments of the study:}

A. The EFL writing skills checklist:

After reviewing literature related to writing skills for EFL students in the advanced level, a checklist was prepared and presented to a group of TEFL and EFL specialists to identify the most important writing skills for the target participants. Based on the jurors' opinions, the following EFL writing skills were addressed in the study:

1. Content-related skills( writing a clearly defined topic sentence, writing specific supporting sentences, writing an appropriate conclusion, and relevancy and adequacy of content). 
2. Style-related skills (cohesion, coherence, word choice and quality of expression, and variety of sentence structure).

3. Writing mechanics (spelling and punctuation).

4. Grammar (verb tenses and correct use of articles, phrasal verbs, prepositions, etc.)

B. The standards checklist for designing the proposed adaptive learning environment.

The main aim of that checklist was to identify the required standards of designing the proposed adaptive online environment. It was derived from various national and world standards documents of designing adaptive environments. The checklist included different standards addressing various design aspects (e.g. content, navigation, interaction, interface, images and graphics, etc.), and it was validated by sending it to some specialists in education technology. The final version of the design standards checklist is presented in (appendix 1).

C. The EFL writing skills test and its analytic rubric:

A writing test was designed for: identifying the level of homogeneity of the control and experimental groups, and determining the participants' pre-and post-levels in the EFL writing skills. The test consisted of two main writing questions. The first question was writing a paragraph describing a given classroom picture, and the second question asked the students to choose one of the two provided topics and write an essay about it. An analytic rubric was designed for assessing and scoring students' answers in the writing test. The rubric used a 4-rating scale since this is believed to distinguish quality and can be easy for scoring. Using an odd number of score points is avoided because of the tendency to gravitate to the mean as the middle score tends to become a "dumping ground" (Arter \& McTighe, 2001) (the test and the rubric are presented in appendix 2).

Reliability of the writing test was estimated through getting the coefficient of internal consistency ( $\alpha$ Cronbach). 15 students other than the main participants of the experimental and control groups were selected to be the sample of the pilot study. The value of ( $\alpha$ Cronbach) was 0.76 which indicated the reliability of the test.

D. The usability scale:

A usability scale was prepared to determine if it was easy for the students to use and navigate through the adaptive learning environment. The scale consisted of (25) items addressing aspects related to simplicity and clarity of using the adaptive environment ( appendix 3).The scale was administered to the pilot participants to estimate its reliability coefficient ( $\alpha$ Cronbach) whose value was 0.70 ; consequently, this value indicated the reliability of the scale. 


\section{Second, designing the adaptive online learning environment:}

Adaptive learning can provide a rich and a flexible environment for meeting students' different skills and needs. Learning in the present study is personalized and tailored using the theory of multiple intelligences as the basis for designing the adaptive environment for improving $2^{\text {nd }}$ year EFL undergraduate students' writing skills.

For designing the proposed adaptive online environment, the main phases of Khamis(2007) and Elgazzar, AbdelLatif E. (2013) were employed as follows:

1. Study and analysis: This phase included studying and analyzing the characteristics of the target participants $\left(2^{\text {nd }}\right.$ year EFL students). Based on the literature and studies previously mentioned in addition to the researchers' direct contact with those students for more than 15 years, it was indicated that those students had a weakness in their writing skills; consequently, they needed to be trained through an up-to-date online environment.

2. Design: This phase included the procedures followed in the design of the adaptive learning environment. These procedures were determining the target objectives of the environment, preparing the content, preparing the learning experiences, and designing the scenario of the online environment. These procedures are explained as follows:

2-1. Target objective of the adaptive environment: The EFL writing skills and the usability of the adaptive environment are the main target objectives.

2-2. Content: The content of the adaptive online environment is mainly activity-based. It is presented in 5 modules (appendix 4) handling the following writing aspects:

a) Steps of process writing (pre-writing, planning, drafting, personal revising, peer revising, editing and proofreading.

b) Paragraph writing (writing appropriate topic sentence, supporting sentences and conclusion while maintaining unity, relevance and adequacy of content).

c) Style-related skills (cohesion, coherence, word choice and quality of expression, and variety of sentence structure).

d) Writing mechanics (spelling and punctuation).

e) Grammar.

The content was adapted according to students' multiple intelligences. For example; for the first group (the analytic group including students with high level of logical-mathematic, musical, and naturalist intelligence), activities included sequential tasks, logic problems, songs, real-life situations, etc.; for the second group (the introspective group including intrapersonal, visual, and existential 
intelligent students), activities were personal reflections, posters, illustrations, etc.; for the third group (the interactive group including linguistic, interpersonal and kinesthetic intelligent students), activities contained interviews, debates, discussions, cooperative tasks, etc. Furthermore, the level of the multiple intelligences-based activities was also adapted according to the writing level of the students. The proposed activities were either at beginning, intermediate or advanced level.

2-3. The learning experiences and materials: The current adaptive environment made use of collaborative working groups through the brainstorming and discussions conducted among the students either via Facebook, Hangouts or WhatsApp in their study of the multiple intelligence-based activities presented in the adaptive modules. The instructor also had the opportunity to communicate with the students and present synchronous lectures through Hangouts. After storing their answers on their personal Googe Drive accounts, students received individualized continuous feedback on their work from the instructor as well as from peers. Based on this feedback, the students were given some corrective activities tailored in terms of their preferences and MI profiles, so that they could reach the mastery level. Students were also exposed to different experiences and materials through online readings, reflections, videos, lesson planning, graphics and pictures.

2-4. Designing the adaptive learning and determining how the student proceeded in the modules presented in the adaptive environment.

For designing the adaptive online environment which is considered as a micro-level adaptive learning system, wherein instruction and tasks are adapted in real time, a number of models were employed. These models are: student model, a domain model, a pedagogical model, a predictive engine and a presentation model. Those models were used for the following functions:

- The student model represents the preferences, characteristics and, in particular, multiple intelligences profile of the learner that is completed using a MI inventory. It is constructed online using the navigation profile and by observing the students' behavior.

- The domain model refers to the way the specific writing skill is structured, the content and the activities that need to be learned. The principles of multiple intelligences were used to 
structure the content model and develop different versions of the same content.

- The presentation model handles the flow of information and monitors the interactions between the user and the system.

- The predictive engine dynamically identifies student's preference for different multiple intelligence resources and informs the pedagogical strategy.

- The pedagogical model uses adaptive presentation and navigation techniques to decide what next to present to the student in terms of content using different pedagogical strategies.

The following figure adopted from Kelly (2005) illustrates the models employed in the present study.

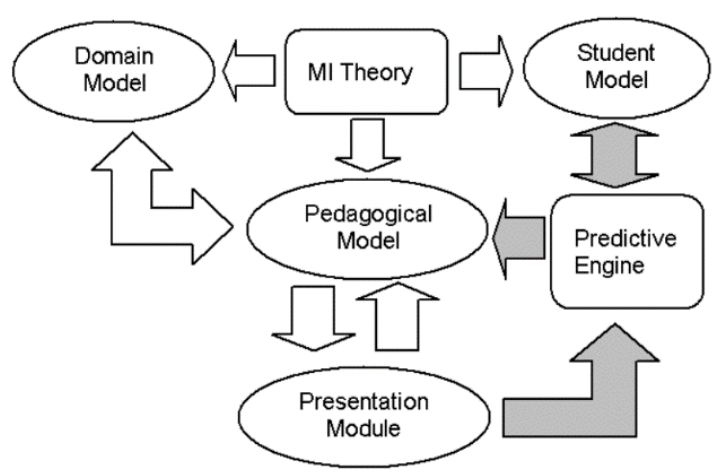

Figure 1: models employed in the adaptive online environment

Concerning the student's flow in the online environment, the following figure illustrates how the student proceeded in the modules presented through the environment. 


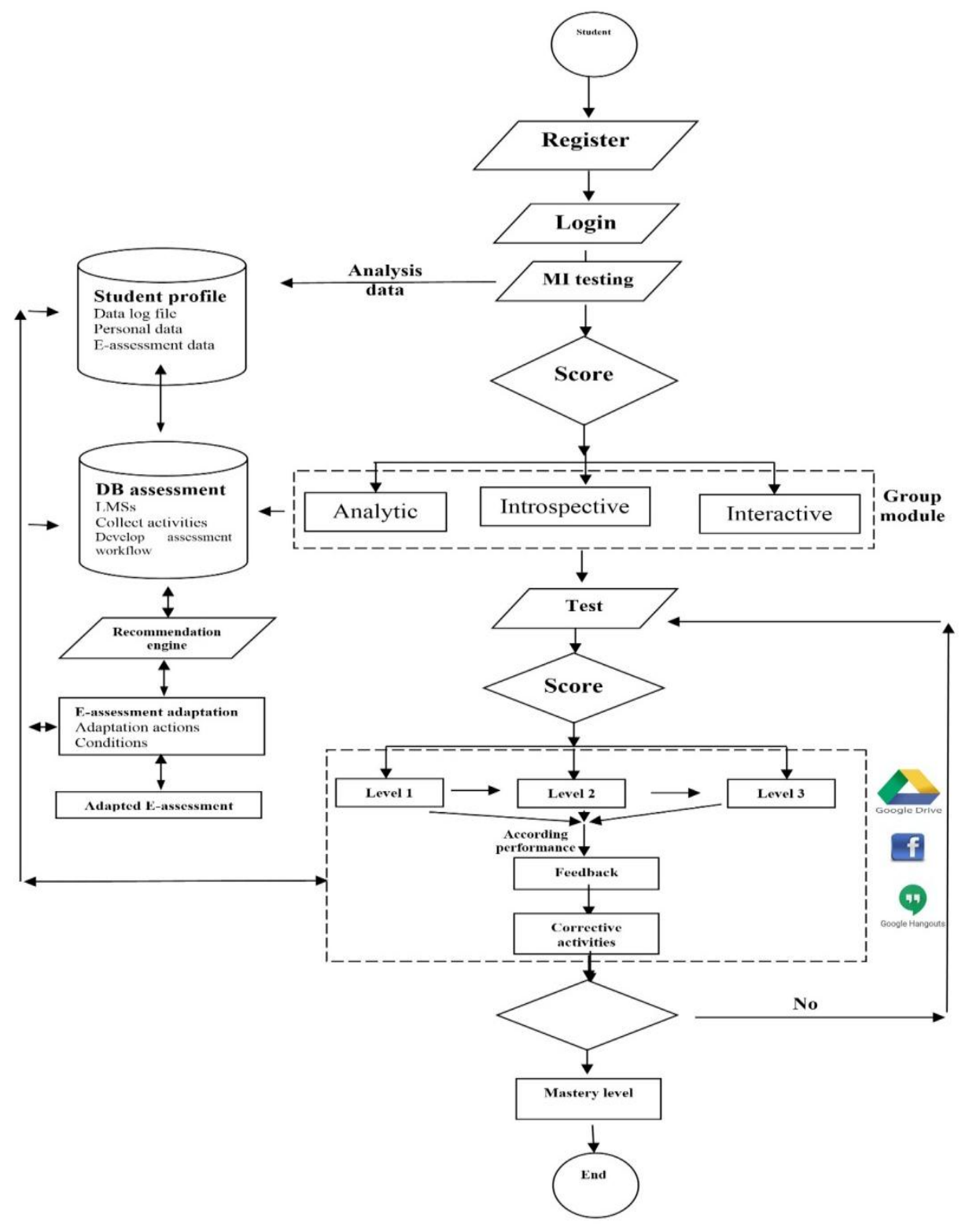

Figure 2. A flowchart of how the student proceeded in the adaptive environment

2-5. designing the scenario of the adaptive online environment.

The scenario is the designed plan for producing the online environment which includes its details and preparation steps, the online tools, multimedia elements, standards, content, instructions, and the other components of the environment. It provides a detailed description of how the written texts are transformed into visuals and videos to form the screens of the environment. The scenario of the adaptive online environment designed for improving EFL undergraduate students' writing skills is presented in appendix 5 . 
3. Technical Implementation: The proposed adaptive online environment is implemented using Java servlet and XML technology. The domain model is stored in XML format and an XML file stores the educational content for each section of material. Individualized student modes are stored dynamically and persistently within a MySQL database. The predictive engine has been developed using Java. The pedagogical manager is implemented in Java. It is responsible for analyzing feedback from the student, updating the student model, retrieving information from the student model, communicating with the predictive engine and making decisions about which instructional strategy to use. The presentation module receives input from the pedagogical manager and manages the presentation of information. It observes, monitors and handles feedback from the student in the form of links activated, buttons pressed and text entered.

\section{Intervention of the study:}

An equivalent group design with one experimental group and one control group was used in the present study. The following steps were followed:

\section{- Pre-application}

The pre-application was administered at the beginning of the first semester of the academic year 2016/2017. Homogeneity between the control group and the experimental group was established through administering the EFL writing skills test to the participants before administering treatment.

Table (1) shows whether there is any significant difference between the control and experimental groups concerning the test preadministration.

Table (1)

T-test of the control and experimental groups on the preadministration of the EFL writing skills test

\begin{tabular}{lccccccc}
\hline \multicolumn{1}{c}{ Skills } & Group & $\boldsymbol{N}$ & Mean & SD & $\boldsymbol{T}$ & $\begin{array}{c}\text { Df } \\
(\mathbf{n 1 + n 2 - 2})\end{array}$ & $\begin{array}{c}\text { Sig. (2- } \\
\text { tailed })\end{array}$ \\
\hline $\begin{array}{l}\text { Content- } \\
\text { related }\end{array}$ & Control & 40 & 38.9 & 1.00766 & 0.8 & 78 & No Sig
\end{tabular}




\begin{tabular}{lccccc} 
skills & & & & & \\
$\begin{array}{l}\text { Style- } \\
\text { related }\end{array}$ & Control & 40 & 37.5 & 1.18 & \\
skills & Exp. & 40 & 37.65 & 1.21 & 0.7 \\
Writing & Control & 40 & 15.4 & 1.03 & 0.2 \\
mechanics & Exp. & 40 & 15.45 & 1.38 & \\
& Control & 40 & 14.38 & 1.39 & 0.1 \\
Grammar & Exp. & 40 & 14.35 & 1.39 & \\
& Control & 40 & 106.2 & 2.56 & \multirow{2}{*}{0.6} \\
Total & Exp. & 40 & 106.6 & 3.38 & \\
\hline
\end{tabular}

The above table indicates that $\mathrm{t}$-value is not significant in the four main skills and in the total score of the writing test; this proves that there is no significant difference between the mean scores of the control and experimental groups on the pre-test. In other words, the homogeneity was established since the two groups are equivalent in their EFL writing skills before applying the experimental treatment.

\section{The experimental treatment:}

The proposed adaptive online learning environment was administered to students of the experimental group. The adaptive environment represented the independent variable in the experimental treatment. The control group studied through a regular Moodle-based course. The experimental treatment was conducted throughout the first semester of the academic year 2016/2017. Procedures of the experimental treatment were:

$\checkmark$ A training session was conducted to the target experimental participants to make sure that they possess the required electronic skills for learning through the adaptive environment. In addition, they were trained on how to use the available online tools, how to access the content of the modules and their activities, how to store their work through Google Drive, and how to make use of the available resources on the adaptive online environment.

$\checkmark$ Students completed the MIDAS (multiple intelligences development assessment scale) MI Inventory (appendix 6) to 
determine their preferred multiple intelligences. Thus, the students were divided into 3 groups. 1) Analytic group, focused on analysis and the thinking processes, including logical-mathematic, musical, and naturalist intelligence. 2) Introspective group, focused on imagination and understanding, including intrapersonal, visual, and existential intelligence. 3) Interactive group, focused on communication and interactive, including linguistic, interpersonal and kinesthetic intelligence. In addition, the experimental students were also classified into three levels (beginning, intermediate and advanced) according to their scores on the pre-EFL writing skills test. Thus, the environment provided various learning paths tailored according to students' individual differences, language levels and intelligences through differentiating the type and level of the activities. Each student proceeded in a personalized learning path working through the activities while interacting with the instructor and peers (via Facebook, WhatsApp or Hangouts), receiving appropriate immediate feedback, and dealing with some corrective activities till reaching the mastery level of all the target writing skills.

\section{- Post- application:}

The post-administration of the instruments was conducted after the experimental treatment to reveal the changes in students' writing skills of both the control and experimental groups. The usability scale was applied only to the experimental group students to determine to what extent the adaptive environment was usable for them.

\section{Results:}

\section{Testing the first hypothesis:}

T-test for independent samples was used to test the first hypothesis which is" There is a statistically significant difference at 0.05 level between the mean scores of the control group and the experimental 
group on the post application of the EFL Writing test in favor of the experimental group". The following table illustrates the results:

Table (2)

Results of t-test of the control and experimental groups on the postadministration of the EFL writing skills test

\begin{tabular}{|c|c|c|c|c|c|c|c|}
\hline Skills & Group & $N$ & Mean & $S D$ & $T$ & $\begin{array}{c}D f \\
(\mathrm{n} 1+\mathrm{n} 2-2)\end{array}$ & $\begin{array}{l}\text { Sig. }(2- \\
\text { tailed })\end{array}$ \\
\hline Content- & Control & 40 & 37.9 & 1.43 & & \multirow{7}{*}{78} & \multirow{7}{*}{$\begin{array}{l}\text { Significant } \\
\text { at } 0.05\end{array}$} \\
\hline $\begin{array}{l}\text { related } \\
\text { skills }\end{array}$ & Exp. & 40 & 59.0 & 1.43 & 65.97 & & \\
\hline Style- & Control & 40 & 42.3 & 1.43 & & & \\
\hline $\begin{array}{l}\text { related } \\
\text { skills }\end{array}$ & Exp. & 40 & 53.95 & 1.4 & 36.9 & & \\
\hline $\begin{array}{l}\text { Writing } \\
\text { mechanics }\end{array}$ & $\begin{array}{c}\text { Control } \\
\text { Exp. }\end{array}$ & $\begin{array}{l}40 \\
40\end{array}$ & $\begin{array}{l}18.45 \\
30.05\end{array}$ & $\begin{array}{l}1.24 \\
1.32\end{array}$ & 40.5 & & \\
\hline Grammar & $\begin{array}{l}\text { Control } \\
\text { Exp. }\end{array}$ & $\begin{array}{l}40 \\
40\end{array}$ & $\begin{array}{c}18.45 \\
29.1\end{array}$ & $\begin{array}{l}1.32 \\
1.19\end{array}$ & 37.9 & & \\
\hline Total & $\begin{array}{l}\text { Control } \\
\text { Exp. }\end{array}$ & $\begin{array}{l}40 \\
40\end{array}$ & $\begin{array}{l}117.1 \\
172.1\end{array}$ & $\begin{array}{c}3.3 \\
3.36\end{array}$ & 73.7 & & \\
\hline
\end{tabular}

Table (2) shows that the mean scores of the experimental group students in the four main writing skills and in the total score were higher than those of the control group. The table illustrates also that the estimated t-value is significant at .05 level. This indicates that there is a statistically significant difference between the experimental and control groups in the four skills and in the total score on the postadministration of the test. This significant difference is in favor of the experimental group. In other words, the experimental group outperformed the control group in the target EFL writing skills.

To get the effect size of the proposed adaptive online learning environment, the square of eta $(\eta 2)$ was estimated after estimating the t-value.

Table (3)

Value of ( $\eta 2)$ and Levels of Effect Size 


\begin{tabular}{|c|c|c|c|c|c|}
\hline $\begin{array}{c}\text { Independ } \\
\text { ent } \\
\text { variable }\end{array}$ & $\begin{array}{c}\text { the dependent } \\
\text { variable }\end{array}$ & $T$ & $\begin{array}{c}D f \\
(n 1+n 2-2)\end{array}$ & $\begin{array}{c}\text { Value of } \\
\text { Eta - } \\
\text { square } \\
\text { (†2) }\end{array}$ & $\begin{array}{l}\text { Level of } \\
\text { effect size }\end{array}$ \\
\hline \multirow{5}{*}{ 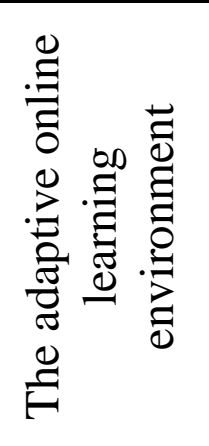 } & $\begin{array}{l}\text { Content- } \\
\text { related skills }\end{array}$ & 65.97 & \multirow{5}{*}{78} & 0.98 & \multirow{5}{*}{ high } \\
\hline & $\begin{array}{l}\text { Style-related } \\
\text { skills }\end{array}$ & 36.9 & & 0.95 & \\
\hline & $\begin{array}{l}\text { Writing } \\
\text { mechanics }\end{array}$ & 40.5 & & 0.96 & \\
\hline & Grammar, & 37.9 & & 0.95 & \\
\hline & Total & 73.7 & & 0.98 & \\
\hline
\end{tabular}

Results in the previous table reflect that the effect size of the adaptive learning environment on the writing performance of the experimental group students in comparison with those of the control group in the four main skills is high. This result indicates that $98 \%$, $95 \%, 96 \%$ and $95 \%$ of the total variance of the four main writing skills (content-related skills, style-related skills, writing mechanics and grammar respectively) can be attributed to the proposed adaptive learning environment. Besides, $98 \%$ of the total variance of the overall writing skills test can be attributed to the independent variable (the proposed adaptive environment).

The significant difference between the experimental and control groups shown in table (2) in addition to effect size shown in table (3) support the effectiveness of the adaptive learning environment in developing students' EFL writing skills; consequently, the first hypothesis of the study is accepted.

\section{Testing the second hypothesis:}

T-test for dependent samples was used to test the second hypothesis which addressed the significant difference between the

* The effect size was estimated using the following formula: $\eta^{2}=\frac{t^{2}}{t^{2}+d f}$ 
experimental group's pre \& post application of the writing skills test. Table (4) shows the results.

Table (4)

Results of t-test of the experimental group on the pre-postadministration of the EFL writing test

\begin{tabular}{cccccccc}
\hline Skills & $\begin{array}{c}\text { Measure- } \\
\text { ment }\end{array}$ & $\boldsymbol{N}$ & Mean & SD & $\boldsymbol{T}$ & $\begin{array}{c}\text { D.f } \\
(\boldsymbol{n}-1)\end{array}$ & $\begin{array}{c}\text { Sig. (2- } \\
\text { tailed })\end{array}$ \\
\hline $\begin{array}{c}\text { Content- } \\
\text { related } \\
\text { skills }\end{array}$ & Pre & 40 & 39.1 & 1.19 & & & \\
$\begin{array}{c}\text { Style- } \\
\text { related } \\
\text { skills }\end{array}$ & Pre & 40 & 59.0 & 1.43 & 83.98 & & \\
Writing & Pre & 40 & 53.65 & 1.21 & & & \\
mechanics & Post & 40 & 15.45 & 1.38 & 64.9 & & \\
Grammar & Pre & 40 & 14.35 & 1.32 & 58.98 & & at 0.05 \\
& Post & 40 & 29.10 & 1.19 & 52 & & \\
otal & Pre & 40 & 106.6 & 3.38 & 159.98 & & \\
\hline
\end{tabular}

Results in the above table illustrate that the estimated t-value is significant at 0.05 level. This reflects that there is a statistically significant difference between the mean scores of the pre-postadministration of the EFL writing skills test in the four main skills and in the total score. This significant difference is in favor of the post-test.

Table (5) illustrates the effect size of the proposed adaptive online learning environment concerning the difference between the pre- and post-application of the EFL writing skills test on the experimental group.

Table (5)

Value of ( $\eta 2)$ and Levels of Effect Size 


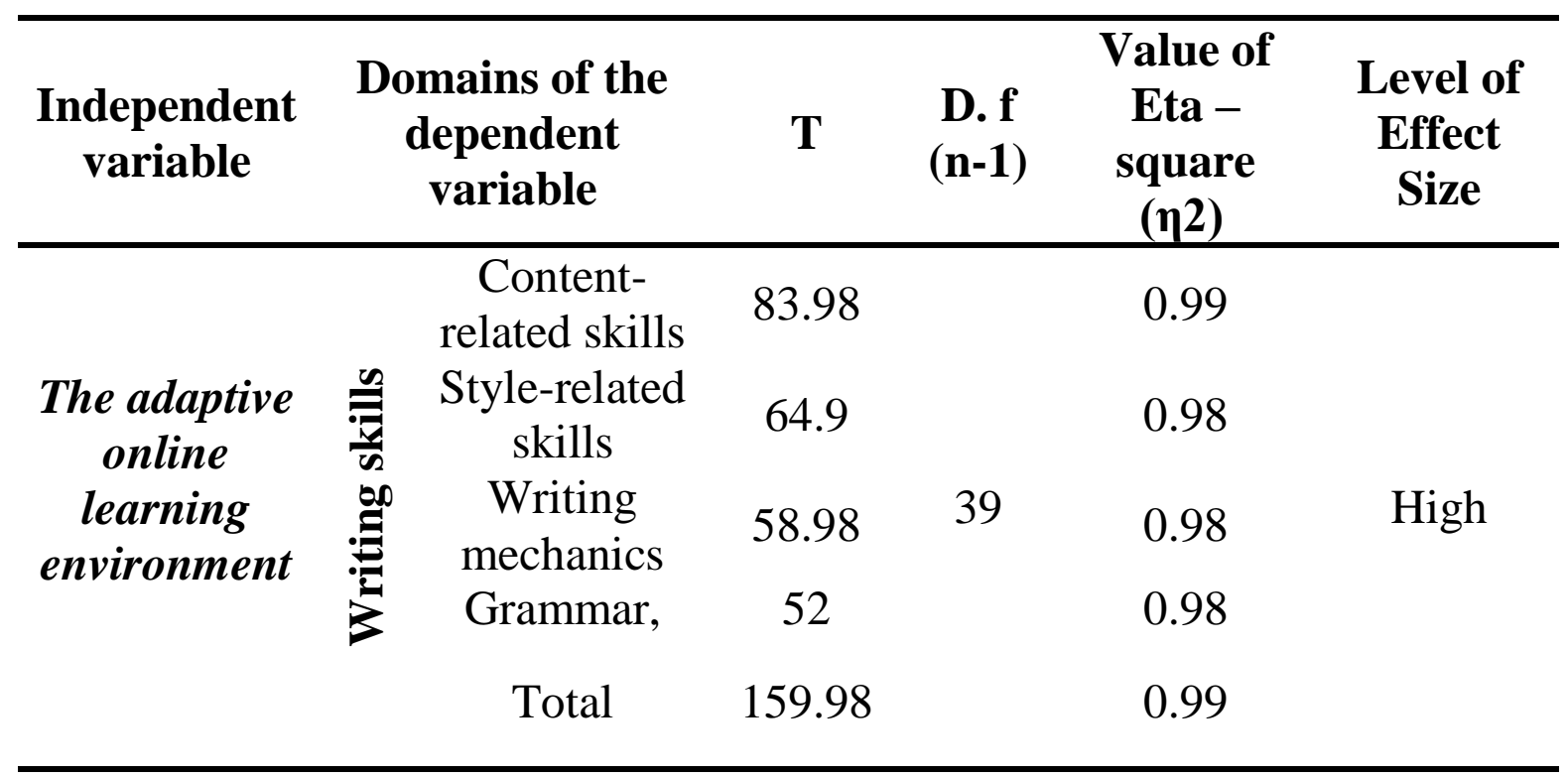

Table (5) illustrates the effect size of the proposed environment on the writing skills of the experimental group students. Results indicate that the effect size is high in the four main skills and in the total writing score. This result indicates that $99 \%, 98 \%, 98 \%$ and $98 \%$ of the total variance of the four main writing skills (content-related skills, style-related kills, writing mechanics and grammar respectively) can be attributed to the proposed adaptive learning environment. Besides, $99 \%$ of the total variance of the overall writing skills test can be attributed to the independent variable (the proposed adaptive environment).

Results in tables (4) and (5) prove that the statistical difference between the pre- post administrations of the EFL writing skills test is in favor of the post-application. In addition, the effect size fosters the positive effect of the adaptive environment on students' writing skills. Therefore, the second hypothesis of the study is proved and accepted.

\section{Testing the third hypothesis:}

The third hypothesis is "The effectiveness of the adaptive learning environment in developing students' EFL writing skills is more than (1.2) when measured by Black's modified gain percentage and more than (0.6) when measured by Mac Gogian's effectiveness percentage". Black's 
modified gain percentage and Mac Gogian's effectiveness percentage were estimated as presented in the following table.

\section{Table (6)}

Pre-post EFL writing skills test's mean scores, Black's modified gain percentage and Mac Gogian's effectiveness percentage

\begin{tabular}{ccccc}
\hline $\begin{array}{c}\text { Maximum } \\
\text { score }\end{array}$ & $\begin{array}{c}\text { Mean scores } \\
\text { of pre-test }\end{array}$ & $\begin{array}{c}\text { Mean scores } \\
\text { of post-test }\end{array}$ & $\begin{array}{c}\text { Black's modified } \\
\text { gain percentage }\end{array}$ & $\begin{array}{c}\text { Mac Gogian's } \\
\text { effectiveness percentage }\end{array}$ \\
\hline 192 & 106.55 & 172.1 & 1.2 & 0.77 \\
\hline
\end{tabular}

As illustrated in the previous table, Black's modified gain percentage is 1.2 and Mac Gogian's effectiveness percentage is 0.77 which is more than 0.6. This indicates that the adaptive learning environment is effective in developing 2nd year EFL students' writing skills; consequently, the third hypothesis is accepted and verified.

\section{Testing the fourth hypothesis:}

The fourth hypothesis addresses if there is statistical significant difference at 0.05 level between the mean scores of the experimental group when applying the usability scale and the hypothetical mastery level $(90 \%)$ in favor of the usability scale.

\section{Table (7)}

\section{Mean score of the usability scale and the hypothetical mastery level}

\begin{tabular}{cccccc}
\hline \hline Tools & Mean & $\begin{array}{c}\text { Difference } \\
\text { between } \\
\text { means }\end{array}$ & T & Df & $\begin{array}{c}\text { Significance } \\
\text { level }\end{array}$ \\
\hline $\begin{array}{c}\text { The usability } \\
\text { scale } \\
\text { The }\end{array}$ & 117 & 4.5 & & & $\begin{array}{c}\text { Significant at } \\
0.05\end{array}$ \\
$\begin{array}{c}\text { hypothetical } \\
\text { mastery level }\end{array}$ & 90 & 9.7 & 39 & \\
\hline
\end{tabular}

Results of table (7) supports the significant difference between the 
mean score of the experimental group on the usability scale (117) and the hypothetical mastery level (90) in favor of the usability scale; thus, the fourth hypothesis is verified and accepted.

\section{Discussion:}

The present study was conducted to explore the effect of designing and implementing an adaptive online learning environment on improving $2^{\text {nd }}$ year EFL undergraduate students' writing skills and usability. The previously mentioned results indicate that the adaptive learning environment based on Gardner's theory of multiple intelligences significantly affected the experimental group students' writing skills as well as their usability of learning through the proposed environment. Meeting students' individual differences, preferences, needs and intelligences may be the reason of such a significant difference. In addition, the adaptive environment was designed to provide personalized content, activities, means of communication, feedback and assessment in light of each individual student's multiple intelligences profile and EFL writing level which directed the student to his/her appropriate learning path.

These findings support the earlier studies carried out on investigating the significance of adaptive learning environments. For example, the results reached by Hussani, Nahvi \& Ahmadi (2013), Asl, Ghassemi and Madadi (2014) and Khodabakhshzadeh \& Kondori (2016) are very consistent with the present study since they supported the use of adaptive e- learning for developing EFL students' different language skills. In addition, Kelly (2005), when examined the effect of an adaptive learning system based on multiple intelligences, emphasized the positive effect of multiple intelligences-based adaptive leaning on students' learning performance and engagement, which is closely related to the results of the present study.

Furthermore, adapting the writing activities according to students' multiple intelligences was very effective in improving their EFL writing skills since such activities fostered students' participation; consequently, they outperformed their counterparts of the control group in their writing scores. This is supported by other studies that handled using multiple intelligences for improving EFL students' writing skills such as El-Masrafy (2003), El-Embaby (2008) and Ahmadian \& Hosseini (2012). 
Since maintaining usability is one of the concerns of implementing adaptive online learning systems, the present study evaluated the usability of the proposed adaptive environment. The previously mentioned results of the usability scale fostered that the environment was usable to a large extent for the target participants. Alshammari, et al. (2016) foster this result as their study indicated that an adaptive elearning system based on learner knowledge and learning style has a higher level of perceived usability than a non-adaptive e-learning system

Besides, throughout the treatment, the proposed adaptive learning environment offered the experimental group students multiple opportunities for interactivity, socialization and practicing group and conversation skills; this was reflected in the students' high level of engagement and participation recorded through the system. This is consistent with the basics of the constructivist-collaborative theory as described by Mödritscher (2007).

\section{Conclusion}

Designing adaptive learning environments that address different learning characteristics can be challenging. This study described how an adaptive learning environment can be tailored according to students' multiple intelligences and language levels to improve their EFL writing skills and usability of the environment. The results suggested that experimental students who learned through the adaptive environment outperformed the control group students who studied through the non-adaptive Moodle-based learning. Moreover, the experimental students emphasized the usability of the proposed adaptive environment for learning and interaction. Future research will shed the light on more variations and models to conduct adaptive learning and on implementing those models with other language skills and domains. 


\section{References:}

Abu Armana, M.(2011). The Impact of a Remedial Program on English Writing Skills of the Seventh Grade Low Achievers. Published M.A. Thesis, Faculty of Education, Gaza University.

Ahmadian, M. \& Hosseini, S. (2012). A Study of the Relationship between Iranian EFL Learners' Multiple Intelligences and their Performance on Writing. Mediterranean Journal of Social Studies, 3(1):111-126.

Al-Onizat, S. H. (2014). The Psychometric Properties of an Arabic Version of Multiple Intelligence Development Assessment Scale for Adolescents (TEEN-MIDAS). Creative Education, 5, 590-605.

Alshammari, M., et al. (2016) 'Usability and Effectiveness Evaluation of Adaptivity in E-Learning Systems ' In: Proceedings of the 2016 CHI Conference Extended Abstracts on Human Factors in Computing Systems, 'ACM Human-Computer Interaction Conference (ACM CHI 2016)'. Held 7-12 May 2016 at San Jose, CA, USA. New York, USA: ACM, 2984-2991. Retrieved December 25, 2016 from http://dx.doi.org/10.1145/2851581.2892395

Arter, J. \& McTighe, J. (2001). Scoring Rubrics in Classroom: Using Performance Criteria for Assessing and Improving Student Performance. California: Corwn Press.

Asl, H. D., Ghassemi, M. and Madadi, A. (2014). The Impact of Cooperative Reading E-Materials Adaptation on Reading Comprehension Performance of Iranian EFL Learners. Journal of Education and Human Development, 3(2), 573-587.

El-Embaby, D. (2008). The Effectiveness of Some MIs Activities in Developing EFL Students' Writing Competencies in the Faculty of Specific Education. Unpublished M.A. Dissertation, Faculty of Education, Zagazig University.

Elgazzar, AbdelLatif E. (2014) Developing eLearning Environments for Field Practitioners and Developmental Researchers: A Third Revision of An ISD Model to Meet eLearning and Distance Learning Innovations. The International Conference on Information Technology in Education (CITE 2014), Engineering Information Institute and the Scientific Research Publishing, Shenzhen, China, January 12-14, 2014.

El-Masrafy, A. (2003). The Effectiveness of a Suggested Multiple Intelligences Theory-based Program in Enhancing EFL Students 
Composition Writing Skills. Journal of Ismailia Faculty of Education. Vol. 3, September.

Franco, C. (2008). Using Wiki-Based Peer-Correction to Develop Writing Skills of Brazilian EFL Learners. Novitas-ROYAL, 2 (1), 49-59.

Francois, C. (2011). What is adaptive learning? Retrieved 24 May 2016 from http://www.wisegeek.com/what-is-adaptive-learning.htm

Gabrielatos, C. (2002). EFL Writing: Product and Process. Eric No. Ed 476839.

Gardner, H. (1983). Frames of Mind: The theory of multiple Intelligences. New York: Basic Books.

Hartley, J. (2008). Academic Writing and Publishing. London: Routledge.

Hassan, S. H. (2016). The Impact of Grammatical Errors on EFL Learners Writing. Unpublished M.A. Dissertation. College of Languages, Sudan University of Science and Technology.

Hussani, K., Nahvi, A. \& Ahmadi, A. (2013). Design and Implementation of an Intelligent Virtual Environment for Improving Speaking and Listening Skills. Interactive Learning Environments, Retrieved January 1, 2017 from: http://www.site.uottawa.ca/ khass103/Papers/NILE2013.pdf .

Isa, F. (2012). The Effect of Using Wikis on Improving Palestinian 9th graders' and their Attitudes towards Writing. M.A. Dissertation, Faculty of Education, the Islamic University of Gaza.

Isleem, H. (2012). A Suggested Program Based on Individualized Activities for Developing Palestinian Sixth Graders' Writing Skills. Ph.D. Dissertation, Islamic University, Gaza.

Johnstone, K.M., et al. (2002). Effects of Repeated Practiceand Contextual Writing Experiences on College Pupils' Writing Skills, Journal of Educational Psychology, 94(2), 305-313.

Kara, N. \& Sevin, N. (2013). Adaptive Learning Systems: Beyond Teaching Machines. Contemporary Education Technology, 4(2), 108-120.

Kellogg, R. T., \& Raulerson, B. A. III. (2007). Improving the writing skills of college students. Psychonomic Bulletin \& Review, 14, 237242.

Kelly, D. (2005). On the Dynamic Multiple Intelligence Informed Personalization of the Learning Environment. Ph.D. Dissertation, Trinity College, University of Dublin. 
Kelly, D. (2008). Adaptive versus Learner Control in a Multiple Intelligence Learning Environment. Journal of Educational Multimedia and Hypermedia, 17(3), 307-336. Chesapeake, VA: Association for the Advancement of Computing in Education (AACE). Retrieved January 19, 2017 from https://www.learntechlib.org/p/24252.

Khamis, M. A. (2015). Adaptive E-learning Environment Systems and Technologies. The First International Conference of the Faculty of Education, Albaha University، during the period 13-15 / 4/2015, Albaha, KSA.

Khodabakhshzadeh, H. \& Kondori, A. (2016). On the Effect of Adaptive Reading Story on Iranian Intermediate EFL Learners' Reading Comprehension Ability. International Journal of Language Learning and Applied Linguistics World, 13 (4), 24-31.

Klašnja-Milićević et al. (2017). E-Learning Systems: Intelligent Techniques for Personalization. Switzerland: Springer.

Li, Q. et al. (2010). Learner Model in Adaptive Learning System. Journal of Information \& Computational Science, 7 (5), 1137-1145.

Murray, M. C., \& Pérez, J. (2015). Informing and Performing: A Study Comparing Adaptive Learning to Traditional Learning. Informing Science: the International Journal of an Emerging Transdiscipline, 18, 111-125. Retrieved June 5, 2016 from: http://www.inform.nu/Articles/Vol18/ISJv18p111125Murray1572.pdf

Mödritscher, F. (2007). Implementation and Evaluation of Pedagogical Strategies in Adaptive E-learning Environments. Unpublished Doctoral Dissertation, Institute for Information Systems and Computer Media, Graz University of Technology. www.iicm.tugraz.at/fmoedritsch_diss.pdf. In Khamis, M. A. (2015). Adaptive E-learning Environment Systems and Technologies. The First International Conference of the Faculty of Education, Albaha University، during the period 13-15 / 4/2015, Albaha, KSA.

Nazim, M. (2012). A Practical Remedy of Common Writing Problems among Students of Writing Skills Courses at Preparatory Year. Published Ph.D. Thesis, Najran University KSA.

Nunan, D. (2003). Practical English Language Teaching. Singa pore:McGraw Hill.

Oxman, S. \& Wong, W. (2014). White Paper: Adaptive Learning Systems. Integrated Education Solutions, Retrieved January 15, 2017 from: 
https://pdfs.semanticscholar.org/4e57/2108fa1591d21d980a6efe786 73edc48c652.pdf

Sonwalkar, N. (2005). Adaptive Learning Technologies: from One Size Fits All to Individualization. Research Bulletin, Issue 7, Retrieved June 19, 2016 from https://net.educause.edu/ir/library/pdf/ERB0507.pdf

Salem, M. S. (2013). The Effectiveness of a Proposed Program Based on Using Workshops in Developing the Functional Writing Skills of Primary Stage Prospective Teachers of English. Unpublished MA Thesis in TEFL, Institute of Educational Studies, Cairo University, Egypt.

Surjono, H. D. (2014). The Evaluation of a Moodle Based Adaptive e-Learning System. International Journal of Information and Education Technology, 4(1), 89-92.

Wang, D. (2005). Urban Splendor: Selected Writings of Wang. A Collection of Essays Discussing the History of Modern Literary Creation in Three Cities: Hong Kong, Shanghai, and Taipei. (7). Cosmos Books, ISBN 988-211-140-8.

Zhang, T., et al. (2007). Using Online Discussions Forums to Assist a Traditional English Class. International Journal on E-Learning, 6(4), 632-643. 